\title{
A Case of Giant Inflammatory Ileal Polyp Removed by Double-Balloon Enteroscopy
}

\author{
Dae Woong Yoon', Beom Jae Lee', Jae Hyoung Lee', Jong-Jae Park', \\ Jae Seon Kim', Young-Tae Bak', Won Jae Choi' and Young Jae Mok ${ }^{2}$ \\ ${ }^{1}$ Division of Gastroenterology, Departments of Internal Medicine and ${ }^{2}$ Surgery, Korea University Medical Center, Seoul, Korea
}

\begin{abstract}
Inflammatory fibroid polyps are rare benign tumors of the GI tract, that commonly present with intestinal obstruction as a result of intussusceptions in the small bowel. A 39-year old man visited our clinic with an asymptomatic polypoid mass in the distal ileum that was identified on abdominal computed tomography for postoperative surveillance after total gastrectomy due to previously diagnosed early gastric cancer. Retrograde double-balloon enteroscopy was performed to diagnose the ileal mass and a complete resection of the polyp was performed using snare for polypectomy without complications. The final histological finding was an ileal inflammatory polyp. Balloonassisted enteroscopy is a valuable modality to diagnose and treat small bowel lesions in lieu of surgical procedures in selected cases.
\end{abstract}

Key Words: Small bowel; Inflammatory polyp; Double-balloon enteroscopy

\section{INTRODUCTION}

Tumors of the small bowel comprise fewer than $2 \%$ of gastrointestinal (GI) malignancies. Benign small bowel tumors are usually asymptomatic, but sometimes can cause small bowel obstruction via the development of intussusceptions. ${ }^{1-7}$

The diagnosis of small bowel lesions is often delayed due to the difficulty of access with conventional endoscopy. However, recent advances allow the entire small bowel to be fully evaluated by capsule endoscopy or balloon-assisted enteroscopy. Balloon-assisted enteroscopy has advantages over other diagnostic modalities for the detection of small bowel lesions due to its capabilities of real-time observation, tissue biopsy and therapeutic intervention. ${ }^{3,8-10}$

We report a case of asymptomatic small bowel inflammatory polyp that was resected endoscopically using double-balloon enteroscopy (DBE) in a patient who previously underwent total gastrectomy.

\footnotetext{
Received: September 29, 2011 Revised: February 27, 2012 Accepted: March 13, 2012

Correspondence: Beom Jae Lee

Department of Internal Medicine, Korea University Guro Hospitial, Korea University College of Medicine, 148 Gurodong-ro, Guro-gu, Seoul 152-703, Korea Tel: +82-2-2626-2003, Fax: +82-2-853-1943, E-mail: L85210@medimail.co.kr

(c) This is an Open Access article distributed under the terms of the Creative Commons Attribution Non-Commercial License (http://creativecommons.org/ licenses/by-nc/3.0) which permits unrestricted non-commercial use, distribution, and reproduction in any medium, provided the original work is properly cited.
}

\section{CASE REPORT}

A 39-year-old man was referred to our department for the evaluation of a small bowel mass detected on abdominal computed tomography (CT). He had previously undergone total gastrectomy due to early gastric cancer (T1NOM0) 7 years before referral. After surgery, abdominal CT scan was performed annually and a $1 \mathrm{~cm}$ ileal mass was detected on the abdominal CT scan 6 years after the operation. But the patient did not want further evaluation and equipments like DBE was unavailable. A repeat abdominal CT scan one year later showed that the mass had increased in size to about $2.5 \mathrm{~cm}$ (Fig. 1). The patient had no associated symptoms. Upon presentation to our clinic, the patient's physical examination and laboratory findings were normal. We first tried conventional colonoscopy, but were unable to access the lesion. Therefore, we performed retrograde DBE (Fujinon EN-450P5/20; Fuji Photo Optical Co., Ltd., Omiya, Japan) and detected a large, pedunculated polyp in the distal ileum, located 50 to $60 \mathrm{~cm}$ from the ileocecal valve. After the injection of an indigocarmineepinephrine mixture at the base of the polyp, a snare polypectomy was performed. Argon plasma coagulation was performed to treat minor bleeding at the polypectomy site (Fig. 2). The total procedure time was 50 minutes. Gross pathologic examination showed a $2.5 \times 2.5 \mathrm{~cm}$ lobulated and peduncu- 

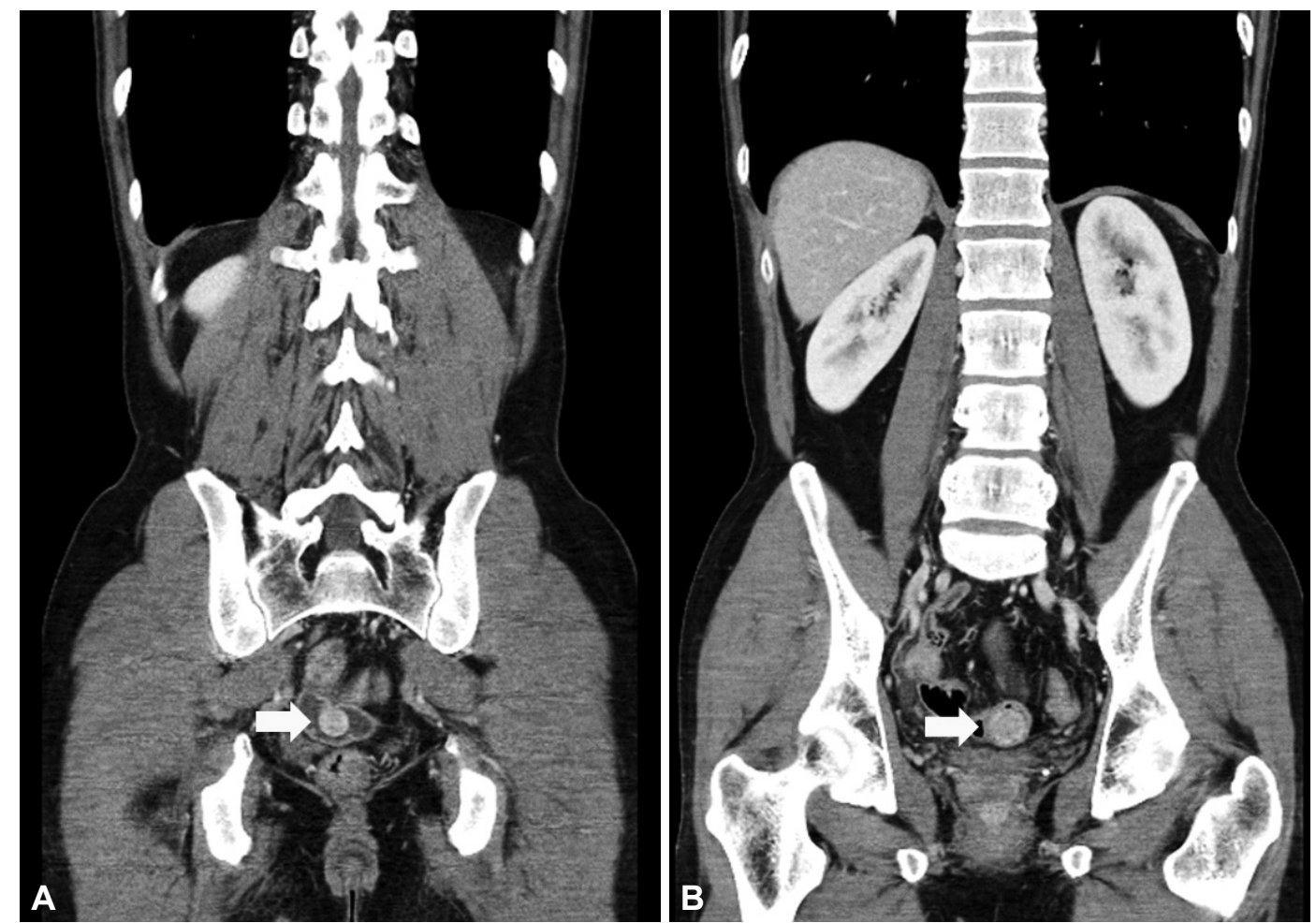

Fig. 1. (A) Abdominal computed tomography (CT) showing an about $1.6 \mathrm{~cm}$ sized polypoid mass in the distal ileum. (B) Increased size of the mass to about $2.5 \mathrm{~cm}$ was noted at abdominal CT findings one year later.
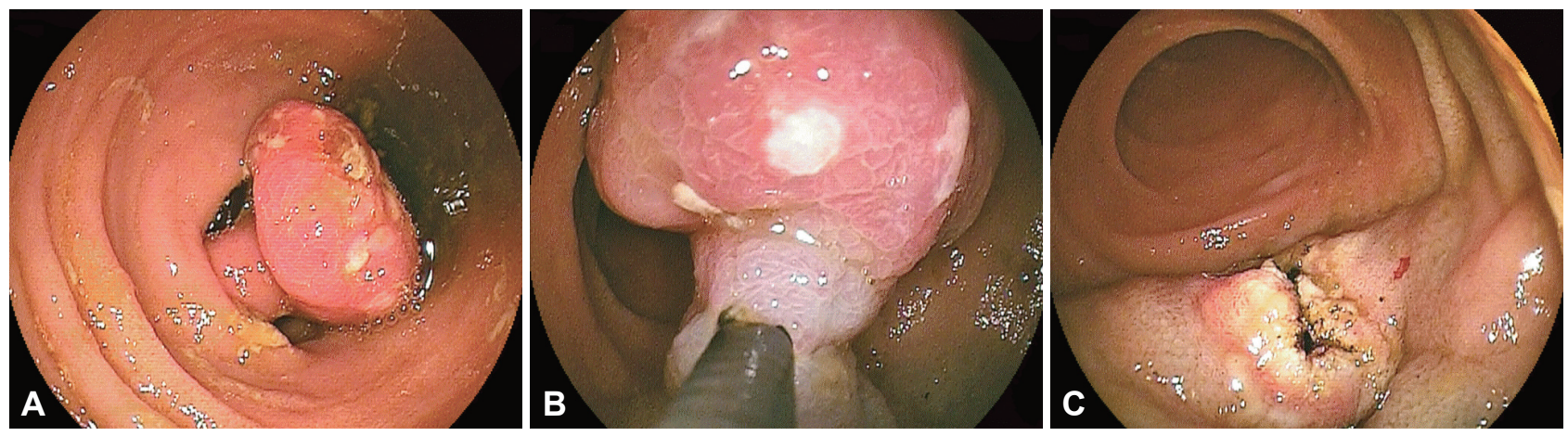

Fig. 2. Double-balloon enteroscopic finding of ileal polyp. A large, pedunculated polypoid nodular mass with scattered whitish pigmentation in the distal ileum, located 50 to $60 \mathrm{~cm}$ from the ileocecal valve. Snare polypectomy was performed after the injection of an indigocarmineepinephrine mixture $(A, B, C)$.

lated polyp with a wide stalk. The results of the histologic examination were consistent with the diagnosis of inflammatory polyp (Fig. 3). The patient was discharged without complications after the procedure.

\section{DISCUSSION}

Inflammatory polyp is a non-neoplastic, proliferating lesion of the gastro-intestinal tract. They most often occur in the stomach, but can occur in any part of the GI tract. Ileal inflammatory polyps are rare benign tumors of the small bowel, and most reports of ileal inflammatory polyps are fibroid polyps that are characterized by the stromal polyps composed of fibrous tissues infiltrated by inflammatory cells, particularly eosinophils. The pathogenesis of inflammatory polyp is unknown, but it is believed that abnormal inflammatory response is associated with the onset process. Microscopically, inflammatory polyps can be mistaken for granulation tissue or sarcoma because of spindle-shape cells. Endoscopically, inflammatory polyps are usually less than $4 \mathrm{~cm}$, but several cases of larger polyps up to $20 \mathrm{~cm}$ have been also reported. There is no clear evidence so far whether the polyp grows to a certain size or continues growing. ${ }^{11}$ In a previous case study, inflammatory polyps were detected in $18 \%$ of the small bowels, with the ileum the most frequent site. Patients with small bowel inflammatory polyps are typically asymptomatic until the on- 

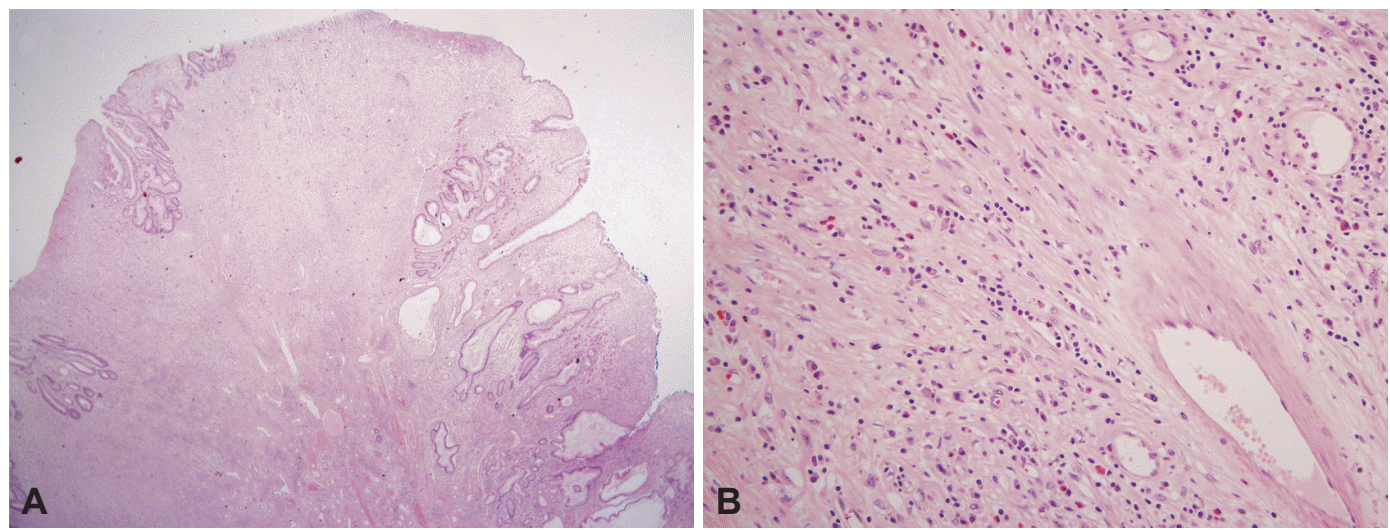

Fig. 3. Hematoxylin \& eosin stain shows an inflammatory polyp. The lesion is submucosal based and extends into the mucosa. (A) Proliferation of the highly vascular fibrous tissue is observed (H\&E-stain $\times 12.5)$. (B) The high magnification view shows proliferation of bland spindle cells with infiltration of mixed inflammatory cells, including eosinophils, lymphocytes, and plasma cells (H \& E stain, $\times 200)$.

set of complications such as small bowel obstruction due to intussusception or bleeding. ${ }^{3,6}$ Most case reports of inflammatory polyps are complicated cases with intussusceptions or bleeding that were diagnosed and treated by surgical resection..$^{1,2,4,5,7}$

Small bowel lesions cannot be evaluated by conventional endoscopy. With recent advances, however, the entire small bowel can now be fully evaluated by balloon-assisted enteroscopy and capsule endoscopy. For example, endoscopic resection of small bowel polyps with DBE is an effective and safe treatment that can prevent emergency surgery due to intussusception in patients with Peutz-Jegher syndrome. Balloon-assisted enteroscopy may be a useful tool for preoperative diagnoses of primary etiology in cases of intussusception, and endoscopic decompression of intussusception may be possible in selected cases. ${ }^{8,10,12}$ Miyata et al. ${ }^{3}$ reported a case of small bowel intussusception due to inflammatory polyp that was preoperatively diagnosed using DBE. Minimal laparoscopic resection could be performed by the shortening intussusception.

Our patient had a past history of abdominal surgery and an asymptomatic ileal mass that increased in size over time. Abdominal CT was unable to characterize the exact nature of this lesion, although a pedunculated mass was suspected. Therefore, the diagnosis of our patient was uncertain due to lack of further evaluation. Using DBE, a large pedunculated polypoid mass with the characteristics of an inflammatory polyp was detected and easily resected with a conventional snare without complications such as bleeding or perforation. Therefore, pathologic diagnosis and therapeutic removal could be achieved simultaneously, and additional surgical procedures could be avoided.

As far as we know, only one other case of inflammatory polyp resected with balloon associated enteroscopy has been reported. Wolff et al. ${ }^{10}$ performed an endoscopic resection of an ileal inflammatory fibroid polyp with a single balloon en- teroscope in a patient who suffered from obscure GI bleeding. With the development of new endoscopic devices, selected small bowel lesions that would previously have been diagnosed and treated by surgery can be detected and treated with balloon-assisted enteroscopy. ${ }^{9}$ For some small bowel lesions that are detected on other diagnostic modalities such as abdominal CT scans, preoperative evaluation with balloon assisted enteroscopy is worthwhile before surgical treatment, and may be helpful to prevent unnecessary surgery. Small bowel inflammatory polyps are appropriate candidates for endoscopic treatment with balloon assisted enteroscopy.

\section{Conflicts of Interest}

The authors have no financial conflicts of interest.

\section{Acknowledgments}

Pathologic examination and photographs of this case are provided by courtesy of Hoiseon Jeong, M.D., from the Department of Pathology, Korea University Guro Hospital, Korea University Medical Center, Seoul, Korea.

\section{REFERENCES}

1. Akbulut S, Sevinc MM, Cakabay B, Bakir S, Senol A. Giant inflammatory fibroid polyp of ileum causing intussusception: a case report. Cases J 2009;2:8616.

2. Gara N, Falzarano JS, Limm WM, Namiki TS, Tom LK. Ileal inflammatory fibroid polyp causing chronic ileocolic intussusception and mimicking cecal carcinoma. World J Gastrointest Oncol 2009;1:89-92.

3. Miyata T, Yamamoto H, Kita H, et al. A case of inflammatory fibroid polyp causing small-bowel intussusception in which retrograde doubleballoon enteroscopy was useful for the preoperative diagnosis. Endoscopy 2004;36:344-347.

4. Mohamud SO, Motorwala SA, Daniel AR, Tworek JA, Shehab TM. Giant ileal inflammatory fibroid polyp causing small bowel obstruction: a case report and review of the literature. Cases J 2008;1:341.

5. Nonose R, Valenciano JS, da Silva CM, de Souza CA, Martinez CA. Ileal intussusception caused by Vanek's tumor: A Case Report. Case Rep Gastroenterol 2011;5:110-116.

6. Gill SS, Heuman DM, Mihas AA. Small intestinal neoplasms. J Clin Gastroenterol 2001;33:267-282.

7. Toydemir T. Inflammatory fibroid polyp of the ileum presenting with small bowel obstruction in an adult patient: a case report. J Med Case 
Rep 2010;4:291.

8. Cazzato IA, Cammarota G, Nista EC, et al. Diagnostic and therapeutic impact of double-balloon enteroscopy (DBE) in a series of 100 patients with suspected small bowel diseases. Dig Liver Dis 2007;39:483-487.

9. Lee BJ, Park JJ, Joo MK, et al. A case of small-bowel intussusception caused by intestinal lipomatosis: preoperative diagnosis and reduction of intussusception with double-balloon enteroscopy. Gastrointest Endosc 2010;71:1329-1332.

10. Wolff JH, Twaddell WS, Darwin PE. Endoscopic resection of an ileal in- flammatory fibroid polyp using retrograde single-balloon enteroscopy. Clin Gastroenterol Hepatol 2009;7:e66-e67.

11. Paikos D, Moschos J, Tzilves D, et al. Inflammatory fibroid polyp or Vanek's tumour. Dig Surg 2007;24:231-233.

12. Xin L, Liao Z, Jiang YP, Li ZS. Indications, detectability, positive findings, total enteroscopy, and complications of diagnostic double-balloon endoscopy: a systematic review of data over the first decade of use. Gastrointest Endosc 2011;74:563-570. 